\title{
Lesions associated with the development of ataxia in vitamin A-deficient chicks
}

\author{
By J. McC. HOWELL \\ Department of Veterinary Pathology \\ AND J. N. THOMPSON* \\ Department of Biochemistry, University of Liverpool \\ (Received 30 fanuary 1967-Accepted 10 April 1967)
}

\begin{abstract}
I. An investigation was made of the sequence of changes that occurred during the development of vitamin A deficicncy in the chick. Particular attention was given to changes in the central nervous system (CNS) and in bone.

2. Groups of birds were killed after being fed the dict for $14,17,20,22,24$ and 28 days. The tissues of five deficient and five control birds were examined unfixed for gross changes and photographed. Groups of five deficient and five control chicks were perfused through the heart with Heidenhain's Susa solution and, after decalcification, the tissues were examined for gross and histological changes. The bones of other groups of five deficient and five control chicks were examined for tetracycline-induced fluorescence.

3. The first lesion seen was metaplasia of the nasal respiratory epithelium to a stratified squamous form. This was rapidly followed by decreased weight gain, the development of ataxia, compression of the CNS and Wallerian degeneration in the ventral and lateral columns of the cervical spinal cord.

4. Changes in bone were first seen in chicks killed 6 days after metaplasia of nasal respiratory epithelium and 3 days after ataxia and brain compression had been seen.

5. Changes were present in the epiphyseal cartilage zone of the femur and in the periosteum of the vertebrae, but not in the epiphyseal cartilage of the vertebrae. The changes in the femur were thought not to have a direct relationship to vitamin A deficiency and may have been produced by inanition.

6. An increase in osteoblast activity and cartilage formation was seen in the vertebral periosteum of the vitamin A-deficient chicks and the relationship of these changes to lesions in the CNS is discussed.
\end{abstract}

There is no completely acceptable explanation of the nerve disorders that affect many species made deficient of vitamin A. Many types of lesion have been described in the nervous tissues of vitamin A-deficient animals (Moore, 1957) and there is a longstanding controversy concerning the existence and significance of changes in bone and in the central nervous system (CNS) of such animals (Wolbach, 1947; Mellanby, 1950; Barnicot \& Datta, 1956; Stewart, I965). We have recently reappraised the problem in poultry and have confirmed that there are macroscopically detectable signs of compression in the CNS of vitamin A-deficient chicks, namely cerebellar flocculi are flattened, cerebral tissue is herniated into venous sinuses and the spinal cord is ridged transversely, particularly in the lumbosacral region (Howell \& Thompson, 1965). Similar changes in vitamin A-deficient birds were described by Wolbach $\&$ Hegsted $($ I952 $b, c)$.

A general theory developed by Wolbach and his associates after experiments with several species of animals (Wolbach, 1947) suggested that vitamin A deficiency did not

* Present address: Department of Poultry Science, Cornell University, Ithaca, New York. 
directly affect nervous tissue but retarded the growth of bone and therefore the expansion of the bony covering of the CNS. The normal increase in size of the CNS was thus obstructed and eventually the nerve tissue was deformed and compressed. Wolbach (1947) suggested more specifically that vitamin A deficiency primarily retarded epiphyseal bone growth and had less effect on appositional deposition and resorption.

Our first report (Howell \& Thompson, 1965) confirmed that signs of compression of the CNS can be consistently demonstrated in vitamin A-deficient chicks, but we did not then pursue Wolbach \& Hegsted's (1952b) arguments concerning the significance of abnormalities in bone growth. Other mechanisms may have been responsible for the compression, such as, for example, an excessive periosteal bone deposition as described by Mellanby (1944) or an overproduction of cerebrospinal fluid as suggested by Woollam \& Millen (1956). Rigdon (1952) described dark degenerating neurones in the spinal cord of vitamin A-deficient ducks and postulated that they were the significant change in the CNS of vitamin A-deficient animals. In our earlier experiments (Howell \& Thompson, 1965) we did not find evidence of a primary effect of vitamin A deficiency on nerve tissue. We did find 'dark' neurones but, as there was no indication of an adjacent cellular response, we considered most of these changes to be artifacts.

Previous studies (Wolbach \& Hegsted, 1952b; Howell \& Thompson, 1965) were concerned with the lesions present after ataxia had developed. The aims of the experiments reported here were to examine and relate the sequence of development of changes resulting from avitaminosis A, including those in the CNS and those in the bones.

\section{EXPERIMENTAL}

One hundred and twenty male birds of 'Thornber's 404 strain were used in the first experiment. They were fed, from time of arrival as day-old chicks, a semi-synthetic vitamin A-free diet (Table I). They were divided into two groups of sixty birds and one group was given, twice weekly, supplements per os of I mg retinyl acetate dissolved in arachis oil. A group of twenty birds, ten deficient and ten controls, was killed by chloroform inhalation after $14,17,20,22,24$ and 28 days on the experiment. Ten of the birds from each group (i.e. five deficient and five controls) were perfused through the heart with Heidenhain's Susa solution after the method of Cammermeyer (196r), and the autopsy was delayed for some hours. The femur, skull and vertebral column were decalcified in trichloroacetic acid. The brain was then dissected out and carefully examined for gross changes, as were saggital sections of the lumbosacral spine. The following tissues from all these birds were examined histologically: cervical cord in transverse section within the atlas or axis, a transverse section of the nose at the level of the commissures of the beak, saggital sections of the spinal cord within the lumbosacral vertebral column, and the lower extremity of the femur. Cerebrum, cerebellum and pons, medulla, various levels of the spinal cord and optic nerves from selected chicks were examined, and sections of lung, oesophagus and kidney were taken from all the chicks killed when they had been 28 days on the diet. Tissues were embedded 
in paraffin wax, cut at $4 \mu \mathrm{m}$ and stained with haematoxylin and eosin. The sections of femur and some of the saggital sections of lumbosacral spine were also stained by toluidine blue and by the alcian blue periodic acid-Schiff technique.

The remaining ten birds from each group were neither perfused nor decalcified. A longitudinal section of the femur, a saggital section of the lumbosacral spine cut to include the glycogen body, and transverse sections of the first four lumbosacral vertebrae were made with a small hackshaw and a sharp scalpel. They were examined with the naked eye and photographed.

Table I. Composition of the vitamin A-free diet

\begin{tabular}{lc}
\multicolumn{1}{c}{ Component } & Amount \\
Vitamin-free casein & $(\%)$ \\
Gelatin & 20 \\
Glycine & I 5 \\
Arginine hydrochloride & I \\
Methionine & $0 \cdot 6$ \\
Arachis oil & $0 \cdot 6$ \\
Vitamin supplement in oil* & 9 \\
Vitamin supplement in glucose $\dagger$ & I \\
Choline chloride in glucoset & I \\
Cellulose powder & I \\
Mineral mixture & 3 \\
Glucose & 6 \\
\end{tabular}

* A solution in arachis oil containing $2 \mu \mathrm{g}$ cholecalciferol and $2 \mathrm{mg}$ DL- $\alpha$-tocopheryl acetate/g.

+ A mixture triturated in glucose containing per $\mathrm{g}$ : cyanocobalamin $3 \mu \mathrm{g}$, biotin $30 \mu \mathrm{g}$, menapthone $100 \mu \mathrm{g}$, folic acid $400 \mu \mathrm{g}$, pyridoxine hydrochloride $800 \mu \mathrm{g}, p$-aminobenzoic acid $800 \mu \mathrm{g}$, riboflavine r.6 mg, calcium pantothenate $2.0 \mathrm{mg}$, thiamine hydrochloride $2.4 \mathrm{mg}$, nicotinic acid xo $\mathrm{mg}$ and inositol to $\mathrm{mg}$.

\$ A mixture of $800 \mathrm{mg}$ glucose and $200 \mathrm{mg}$ choline chloride.

$\S$ Salts $G$ of Fox \& Briggs (r 960 ) with the following additions to each $60 \mathrm{~kg}: \mathrm{Na}_{2} \mathrm{MoO}_{4} \cdot 2 \mathrm{H}_{2} \mathrm{O} 5 \mathrm{~g}$, $\mathrm{Na}_{2} \mathrm{SeO}_{3} 200 \mathrm{mg}, \mathrm{NaF} 500 \mathrm{mg}, \mathrm{CoCl}_{2} .6 \mathrm{H}_{2} \mathrm{O} 2 \mathrm{~g}, \mathrm{H}_{3} \mathrm{BO}_{3} 10 \mathrm{~g}, \mathrm{~K}_{2} \mathrm{Al}_{2}\left(\mathrm{SO}_{4}\right)_{4} .24 \mathrm{H}_{2} \mathrm{O} 5 \circ \mathrm{g}_{2} \mathrm{Na}_{2} \mathrm{SiO}_{3}$. ${ }_{9} \mathrm{H}_{2} \mathrm{O}{ }_{5} \mathrm{~g}$.

In the second experiment fifty male birds of Thornber's 404 strain were bought as day-old chicks and were divided into two groups of twenty-five, a deficient group and a control group. The diets and supplements were similar to those given to the birds in the first experiment. When they had been given the diet for to days they were given an intra-abdominal injection of $5 \mathrm{mg}$ tetracycline/100 g body-weight. Subsequently groups of at least eight chicks (four deficient and four controls) were killed after they had been on the experiment for $14,17,20,22$ and 24 days. Several vitamin A-deficient chicks that died were also examined. The atlanto-occipital joint of the birds was disarticulated and the heads were fixed in neutral formalin. Longitudinal sections of the femur and saggital sections of the lumbosacral spine were made from the unfixed fresh tissue, cleaned with a stiff-bristled brush, and examined for fluorescence under ultraviolet light. The fixed brain was dissected from the undecalcified skull and examined for evidence of compression. 


\section{RESULTS}

In the vitamin A-deficient chicks metaplasia of the nasal respiratory epithelium to the stratified squamous form was seen in two of the five birds examined after $\mathrm{I}_{4}$ days on the diet (Pl. I $a$ ). Squamous metaplasia of nasal respiratory epithelium and ataxia were seen in three of the five deficient chicks killed after $I 7$ days on the experiment. The CNS of one of these birds was compressed. Squamous metaplasia of respiratory epithelium, ataxia and compression of the CNS were seen in all birds that had been fed the deficient diet for more than 22 days. The details of the changes seen in groups of chicks are given in Table 2, and the changes seen in individual birds killed after 14, I6 and 20 days on the diet are given in Table 3 .

Abnormalities were not found in any of the control birds killed on the $14^{\text {th }}, 17^{\text {th }}$, $24^{\text {th }}$ or 28 th day of the experiments. Two of the five control birds examined histologically on the 2oth day and one of the five control birds examined on the 22nd had a small focus of metaplastic change to stratified squamous epithelium in the respiratory epithelium of the nose. These were small foci associated with slight submucosal inflammation. No other abnormality was seen in these birds.

Gross lesions seen in the central nervous system were as described previously (Howell \& Thompson, 1965) and included herniation of cerebral tissues into venous sinuses, flattening of the cerebellar flocculi and transverse ridging of the spinal cord.

Histological changes were seen in the white matter of the upper cervical cord where there was pronounced axon swelling, which appeared to be confined to the ventral and lateral columns (Pl. I $b$ ). Reactive gliosis was not seen and few gitter cells were present. The process was early Wallerian degeneration.

Counts were made of the number of 'dark' neurones in one section of the cervical cord of each chick. They were found in eighteen of the sixty chicks; twelve were vitamin A-deficient and six were controls. A total of fifty-four dark neurones were found, forty-one in the deficient chicks and thirteen in the control chicks. Their occurrence could not be correlated to ataxia nor to the presence of gross lesions in the CNS (Tables 2 and 3 ).

Longitudinal sections of the lower extremity of the femur and saggital sections of the lumbosacral spine were examined macroscopically and histologically from the five control and five deficient chicks whose details are given in Table 2. Lesions were found in the femurs of deficient chicks and consisted of an increase in the depth of the epiphyseal cartilage (Wolbach \& Hegsted, I952a) and a decrease in the vascular tunnelling (Pl. I $c, d)$. Osteoclasts and osteoblasts were numerous. The marrow cavity immediately below this area of cartilage contained fibroblastic tissue rather than haemopoietic tissue.

Images of sections of the femurs were projected from a photographic enlarger and were printed directly on photographic paper. This procedure enabled the structure of bones from larger numbers of chicks to be compared simultaneously. These 'negative' prints were obtained with the groups of five deficient and five control birds killed at varying stages of development of the deficiency disease (Table 2). Evidence of abnormalities in and below the epiphyseal cartilage zone of the femur was seen in the 
Vol. 21

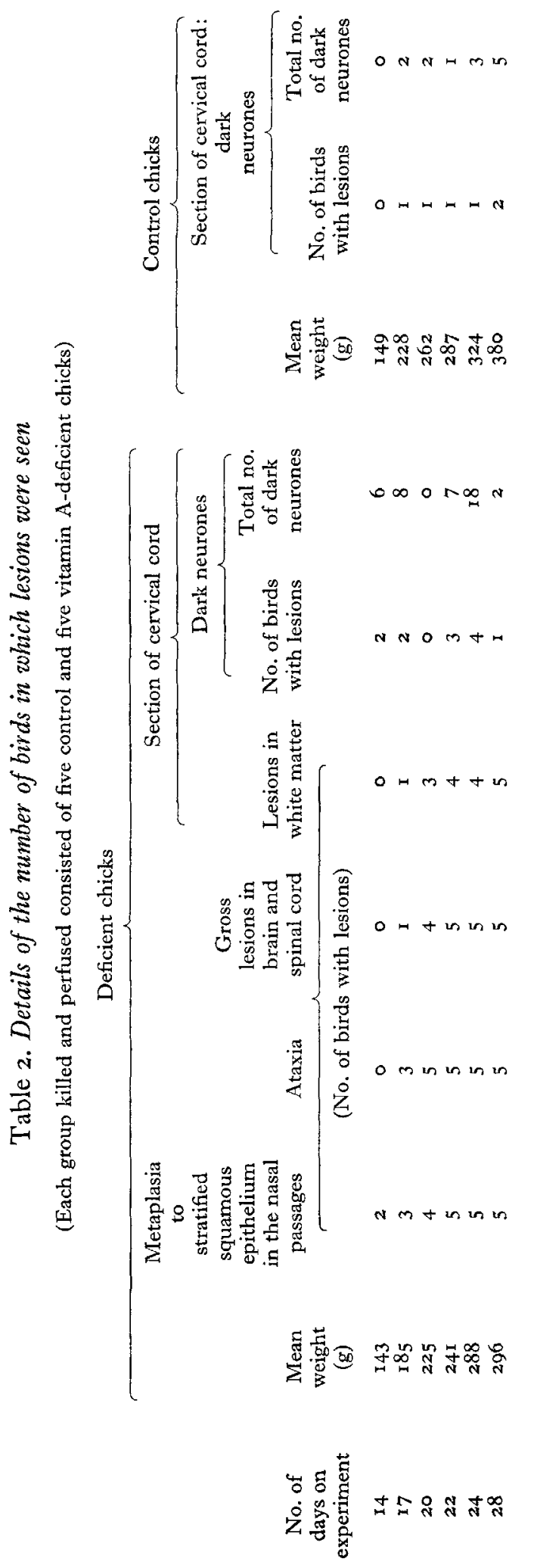


deficient chicks killed when they had been fed the diet for 20 days. The changes were not seen in any of the chicks killed at an earlier age, but were severe in chicks killed after 24 days on the diet (see Pl. I c ). There were no obvious differences in the periosteum and subperiosteal bone of the deficient and control chicks.

Saggital sections of the lumbosacral spine were examined histologically and 'negative prints' of individual vertebral bodies were obtained as described previously. Evidence of abnormal endochondral bone growth was not apparent ( $\mathrm{Pl} .2 a, b)$. However the periosteal bone was less compact and the subperiosteal osteoblasts were more numerous in the deficient birds killed after 20 days on the experiment (Pl. $2 c, d$ ). These changes were more marked in older chicks, and in many of them subperiosteal cartilage formation had occurred. The cartilage was most often found below the periosteum on the dorsal surface of the vertebral canal posterior to the glycogen body (Pl. $3^{a}$ ).

Table 3. Details of changes seen in three of the groups of five deficient chicks

\begin{tabular}{|c|c|c|c|c|c|c|}
\hline \multirow{2}{*}{$\begin{array}{c}\text { No. of } \\
\text { days on } \\
\text { the } \\
\text { experiment }\end{array}$} & \multirow[b]{2}{*}{$\begin{array}{l}\text { Weight } \\
\text { (g) }\end{array}$} & \multirow{2}{*}{$\begin{array}{l}\text { Metaplasia to } \\
\text { stratified } \\
\text { squamous } \\
\text { epithelium } \\
\text { in the nasal } \\
\text { passages }\end{array}$} & & \multirow{2}{*}{$\begin{array}{l}\text { Gross lesions } \\
\text { in brain and } \\
\text { spinal } \\
\text { cord }\end{array}$} & \multicolumn{2}{|c|}{ Section of cervical cord } \\
\hline & & & Ataxia & & $\begin{array}{l}\text { Lesions in } \\
\text { white matter }\end{array}$ & $\begin{array}{c}\text { No. of dark } \\
\text { neurones }\end{array}$ \\
\hline \multirow[t]{5}{*}{14} & I $5 \circ$ & + & 0 & 0 & $\circ$ & 0 \\
\hline & I 28 & + & 0 & 0 & $\circ$ & 5 \\
\hline & 149 & 0 & 0 & 0 & 0 & I \\
\hline & 146 & o & o & o & 0 & o \\
\hline & I4I & $\circ$ & $\circ$ & $\circ$ & $\circ$ & $\circ$ \\
\hline \multirow[t]{5}{*}{ I 7} & I74 & + & + & + & + & 7 \\
\hline & r99 & + & + & 0 & $\circ$ & 0 \\
\hline & $\mathrm{I} 84$ & + & + & 0 & o & I \\
\hline & 199 & $\circ$ & 0 & 0 & $\circ$ & 0 \\
\hline & I7I & $\circ$ & 0 & 0 & 0 & 0 \\
\hline \multirow[t]{5}{*}{20} & 234 & + & + & + & + & o \\
\hline & 207 & + & + & + & + & 0 \\
\hline & 260 & + & + & + & + & 0 \\
\hline & 186 & + & + & + & 0 & 0 \\
\hline & 240 & 0 & + & 0 & 0 & 0 \\
\hline
\end{tabular}

Groups of ten chicks, five deficient and five control, were killed after I4, I7, 20, 22 and 28 days on the experiment and were not perfused. Longitudinal sections of femur and transverse sections of the anterior series of lumbosacral vertebrae were examined macroscopically and photographed. Gross abnormalities were not detected in either size or contour of the bones from deficient chicks nor was there any evidence of a marked reduction in the diameter of the vertebral canal ( $\mathrm{Pl} .3 b, c)$.

In a second experiment in which chicks were given tetracycline as a bone marker, longitudinal sections of femur and saggital sections of the lumbosacral spine were examined for recent bone growth under an ultraviolet lamp. Little difference was seen between the two groups of birds in the amount or distribution of fluorescence until the chicks had been fed the diet for 22 days. In the groups of chicks killed after 22 and 24 days on the experiment fluorescence was more prominent in the vertebrae of the control groups. In the vertebrae of deficient chicks killed at these times fluorescence 
could readily be seen on the cut surface of bone but was not seen on the uncut bone surface of the wall of the vertebral canal. This difference in fluorescence between control and deficient chicks was particularly obvious on the lateral walls of the vertebral canal in and adjacent to the area that had been occupied by the glycogen body.

\section{ISCUSSION}

The examination of chicks given a vitamin A-deficient diet and killed before and during the development of signs of deficiency has extended our previous observations (Howell \& Thompson, r965), which were confined almost entirely to severely deficient birds. The first lesion to appear in chicks given the deficient diet was a metaplastic change in the nasal respiratory epithelium (Pl. I $a$; Tables 2 and 3 ). Two chicks examined after 14 days on the diet showed this lesion without any other detectable abnormality. Thereafter several chicks showed signs of ataxia, and the rate of growth of the deficient birds fell below that of the controls. Metaplasia of the nasal epithelium was displayed by all but one of the birds having other indications of vitamin A deficiency. We thus agree with Jungherr (1943) that histological change at this site is a sensitive indicator of vitamin A deficiency in the chick.

Of the twenty-three ataxic birds, twenty showed signs of compression of the CNS on post-mortem examination. Difficulty might be expected in detecting macroscopically the early stages of compression of the CNS as our fixation and decalcification techniques produced some shrinkage of soft tissues. Histological examination of the frontal pole of the brain in situ (Howell \& Thompson, 1965) may have revealed cerebral herniation in such mildly ataxic birds.

We found little evidence for a direct effect of vitamin A deficiency on nerve tissue. Previously we disputed the claim (Rigdon, 1952) that 'dark' neurones in the CNS of vitamin A-deficient birds indicated a specific effect of vitamin A deficiency. In the experiments reported here the birds were perfused by the method developed by Cammermeyer (1961), so as to reduce artifacts to a minimum. This resulted in a much smaller number of 'dark' neurones than had been seen in our previous study (Howell \& Thompson, 1965). We consider that most 'dark' neurones are artifacts; the remainder could have been caused by compression of the CNS during life and they are unlikely to be a primary product of vitamin A deficiency.

Nerve fibre degeneration of the white matter of the cervical cord was first seen in a severely ataxic deficient chick that had been receiving the diet for $\mathbf{r} 7$ days. This bird had compression of the CNS. The lesion was seen in three of the four birds with compression of the CNS killed after 20 days on the diet, in four of the five deficient birds killed after 22 and 24 days and was present in all the vitamin A-deficient birds killed after 28 days on the experiment (Tables 2 and 3 ). Myelin degeneration in the spinal cord had previously been demonstrated in the cervical cord of a small number of vitamin A-deficient chicks by Howell \& Thompson (1965), using the Marchi technique. Degeneration of the white matter of the cervical cord was only found in ataxic chicks with signs of compression and was probably produced by trauma to axons and nerve cell bodies. 
Many workers have tried to elucidate the cause of the compression of the CNS. Wolbach (1947) suggested that compression occurred in vitamin A deficiency because the nervous system continued to grow at a normal rate whilst the growth of the skull and vertebrae was retarded. The retardation in bone development was related mainly to endochondral sequences with little impairment of appositional growth. Attempts to confirm or reject this theory by direct measurement of the dimensions of the vertebrae and of the spinal canal (Pl. $3 b, c)$ proved inconclusive. Wolbach (I947) bases his hypothesis on the appearance of histological abnormalities in the regions of endochondral growth. Wolbach \& Hegsted $\left(195^{2} b\right)$, investigating the lesions in ataxic vitamin A-deficient chicks, stated that 'All sequences concerned in skeletal growth are retarded before growth as a whole (estimated by weight increase) is materially affected and before there is extensive replacement of glandular epitheliums by stratified keratinizing epithelium.' Our results are at variance with this statement. Histological evidence of abnormal bone development was first seen when the chicks had been given the diet for 20 days. The average weight of this group of deficient chicks was below that of the control group. The chicks in the vitamin A-deficient group killed after I7 days also had an average weight below that of their control group; three were ataxic and had metaplastic changes in their respiratory epithelium (Tables 2 and 3 ), but bone changes were not detected in this group of chicks.

The changes seen in the epiphyseal cartilage of the femur of our vitamin A-deficient chicks were similar to those observed by Wolbach \& Hegsted (1952b). However, these authors observed retardation or complete inactivity of growth in regions of endochondral ossification in vertebrae. We did not see changes in endochondral bone growth in the vertebrae of our vitamin A-deficient chicks (Pl. 2a).

The lesion in the epiphyseal cartilage of the long bones is not specific to vitamin A deficiency but, for example, has been seen in copper-deficient chicks (Carlton \& Henderson, 1964). The changes in the long bones of our vitamin A-deficient chicks were not observed until their body-weight was less than that of the controls. Changes in the epiphyseal cartilage were accompanied by replacement of haemopoietic tissue by a loosely arranged fibroblastic tissue. These changes could be due to inanition although their histological appearance is different from that described by Pratt \& McCance (1960) in the long bones of cockerels held at fixed weights by giving sufficient food for survival only. Wolbach (1947) wrote of the changes in the epiphyseal cartilage of vitamin Adeficient animals, 'The resulting appearance is similar to that produced by inanition from inadequate amounts of a perfect diet, or by inanition resulting from other vitamin deficiencies not specifically related to bone growth, such as riboflavin and pyridoxine.'

Our results suggest that abnormality in endochondral bone growth is a terminal feature of vitamin A deficiency and is probably a non-specific effect of inanition. We have no evidence of abnormalities in endochondral growth in vertebrae that would account for compression of the CNS. Wolbach's argument can only be applied to growing animals and conclusive evidence against it has now been obtained in experiments to be described elsewhere (Howell \& Thompson, I967), in which nerve disorders and compression of the CNS similar to that observed in the chick have been demonstrated in adult non-growing birds deprived of vitamin $\mathrm{A}$. 

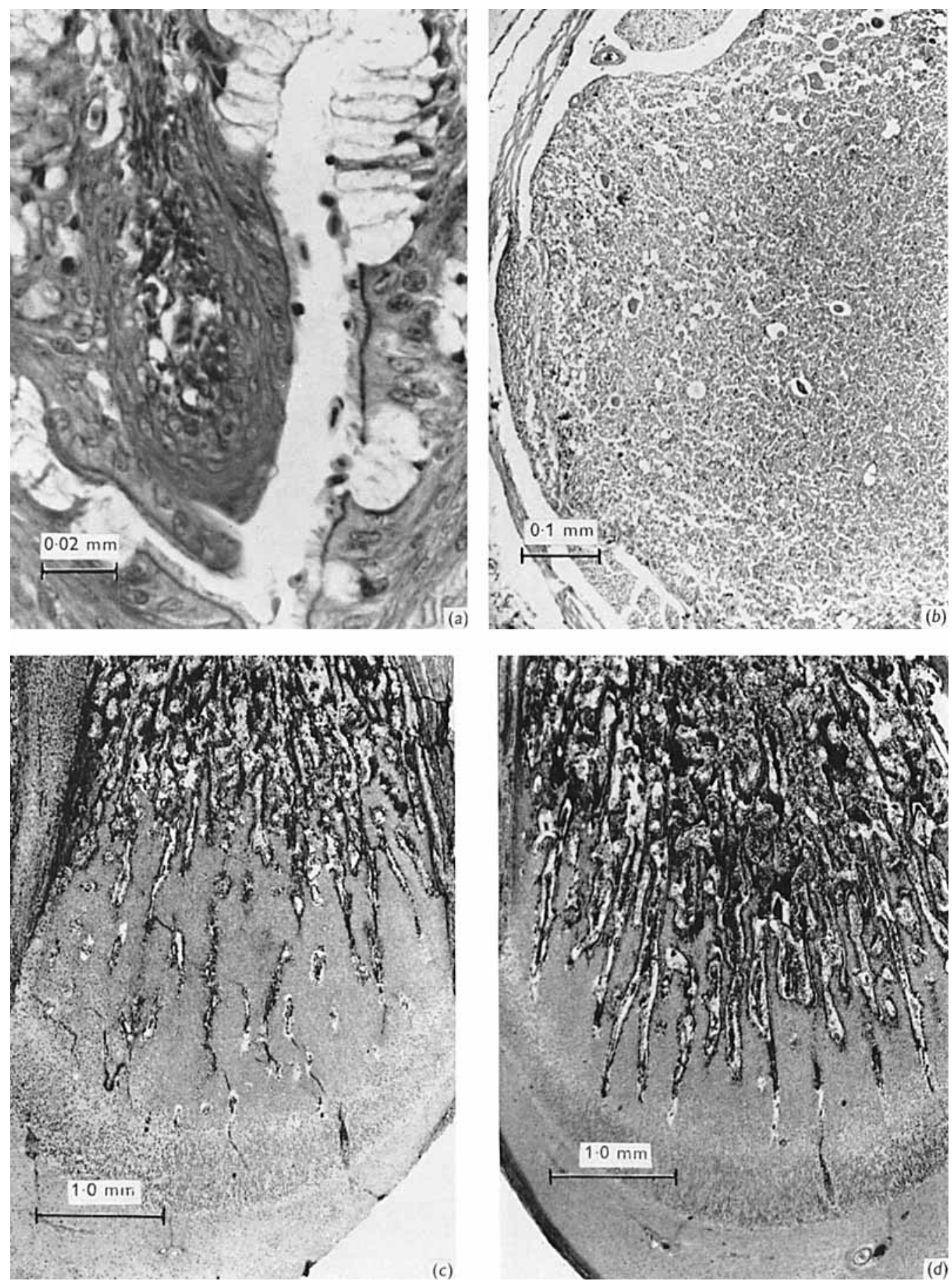

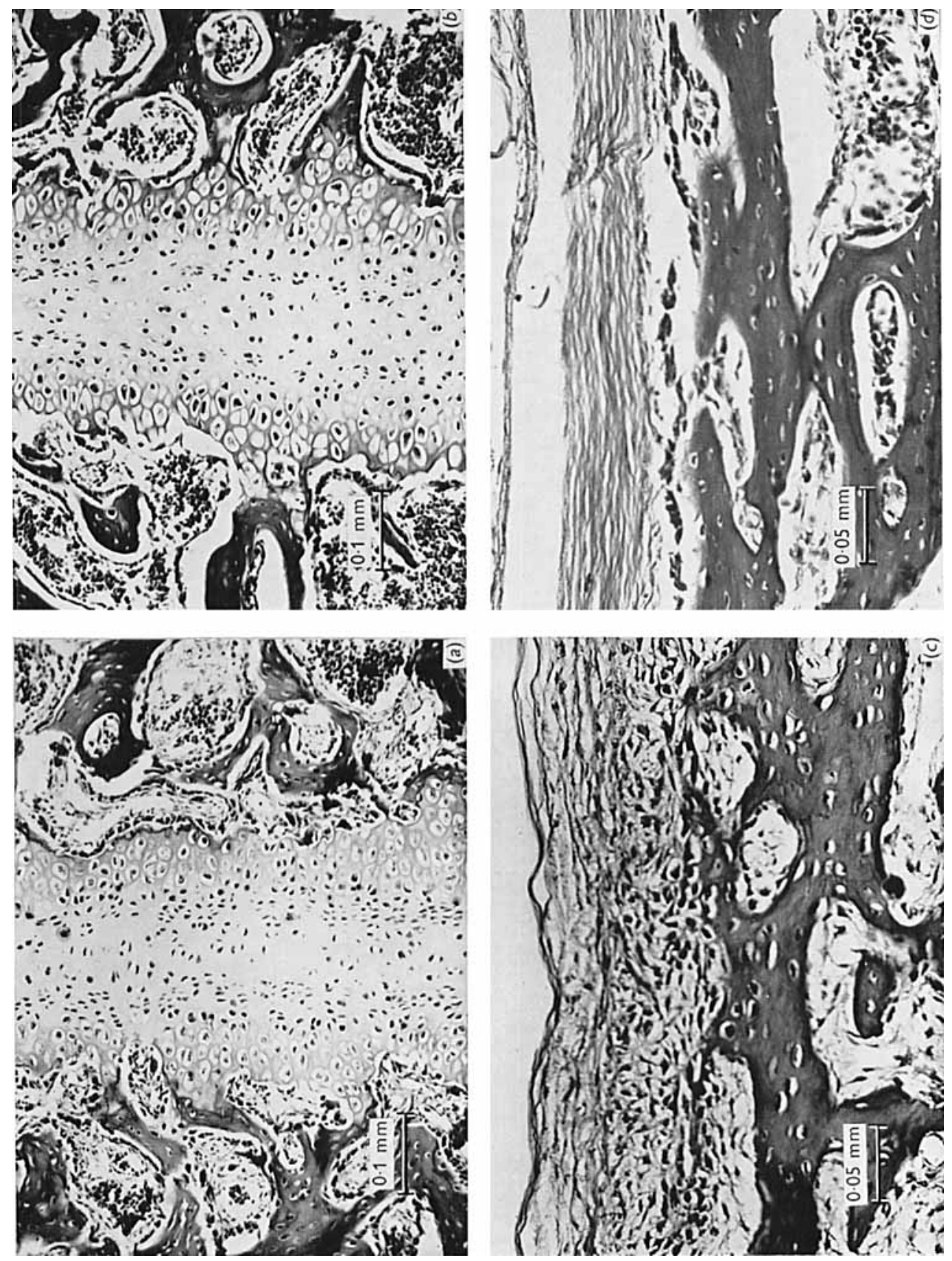
British Fournal of Nutrition, Vol. 2 I, No. 3

Plate 3
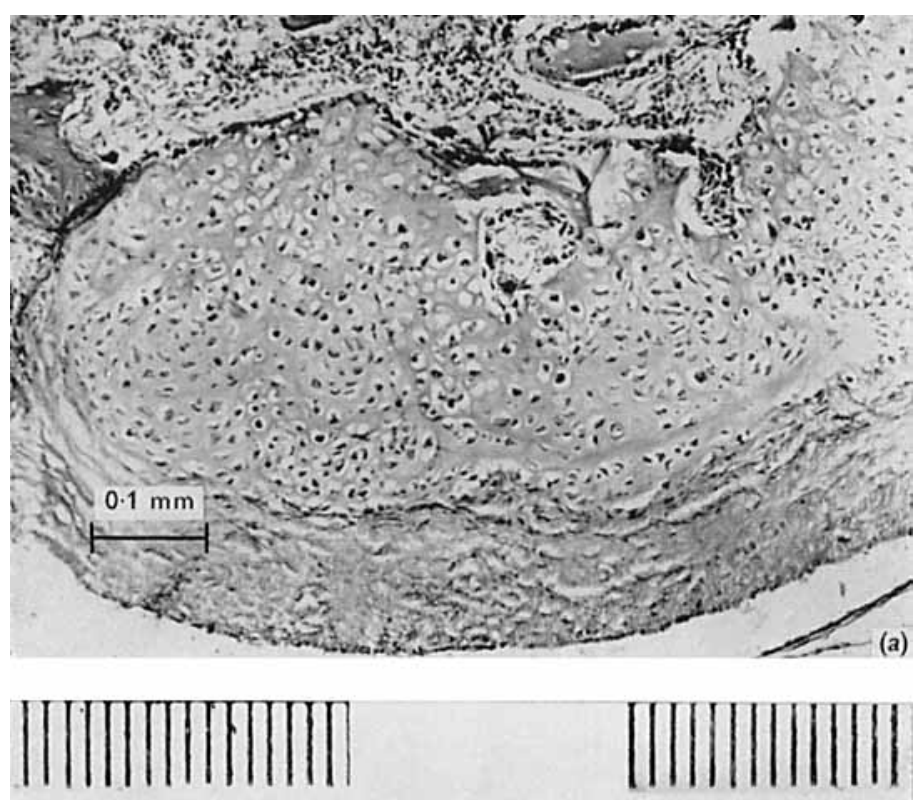

(b)
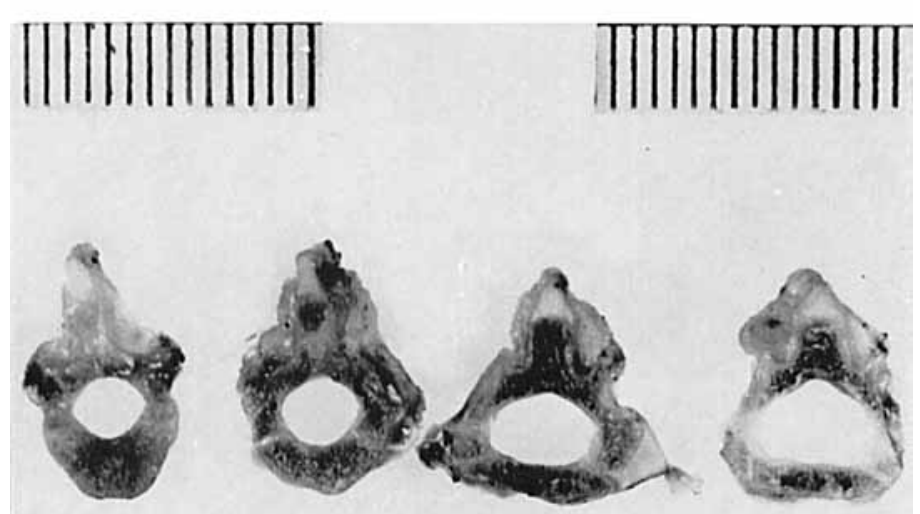

(c)

J. MCC. HOWELL AND J. N. THOMPSON 
The changes that we saw in the subperiosteal tissue (Pl. $2 c$ and $3 a$ ) may be of great importance in the development of CNS compression in the vitamin A-deficient chick. Mellanby ( $1944,195^{\circ}$ ) regarded changes in the periosteum to be of primary importance in producing compression of nervous tissue in vitamin A-deficient dogs, rats and rabbits. Increased growth of periosteal bone has been observed in the vitamin Adeficient rat (Covell, I940; Irving, I956) and rabbit (Perlman, I949). The subperiosteal changes were well developed in the chicks killed after 20 days on the experiment, and enough tissue was present in the vitamin A-deficient chicks to mask the fluorescent bone beneath. Change in the periosteum was not seen in the ataxic chicks killed after I 7 days on the diet, but it is difficult to assess anything other than gross overactivity in a tissue that is already actively growing. A small alteration in the diameters of an irregularly shaped tube such as the vertebral canal can produce a marked alteration in its volume and in the shape of its contents. This may have happened in the chicks, but similar changes should be much more obvious at an earlier stage in future experiments planned with non-growing adult birds. Further investigations of bone pathology and measurements of cerebrospinal fluid pressure in vitamin A-deficient birds are now being undertaken.

We wish to thank Professor D. L. Hughes and Professor R. A. Morton, FRS, for encouragement and advice; Mrs M. W. Harling, AIMLT, and Mrs C. McLaughlin for technical assistance, and Mr G. Weston, FIMLT, and Mr E. O'Neill for the photographs. J. N. Thompson is a British Egg Marketing Board Fellow. The work was supported by a grant from the British Egg Marketing Board.

\section{EXPLANATION OF PLATES}

\section{Plate I}

All sections were stained by haematoxylin and eosin.

(a) Nasal respiratory epithelium of a chick that had been given the vitamin A-free diet for I 4 days. In the centre of the field the ciliated columnar respiratory epithelium has undergone squamous metaplasia.

(b) Lateral column of the upper cervical spinal cord of a chick that had been given the deficient diet for 20 days. Numerous swollen axons are present.

(c) Lower extremity of the femur of a chick given the deficient diet for 24 days. The epiphyseal cartilage has increased in depth and there are few vascular tunnels (cf. $(d)$ ).

(d) Lower extremity of the femur of a chick given the deficient diet and a supplement of vitamin $\mathrm{A}$ for 24 days. This is a normal bone.

\section{Plate 2}

All sections were stained by haematoxylin and eosin.

(a) Section of the cartilage between the sixth and seventh lumbosacral vertebrae of a chick given the vitamin A-free diet for 24 days. Normal endochondral growth.

(b) Section of the cartilage between the sixth and seventh lumbosacral vertebrae of a chick given the deficient diet supplemented with vitamin A for 24 days. This is normal tissue.

(c) Longitudinal section of the dorsal surface of the body of the sixth lumbosacral vertebra of a chick given the deficient diet for 20 days. The periosteum is very cellular; many of the cells are osteoblasts (cf. (d)). 
(d) Longitudinal section of the dorsal surface of the body of the sixth lumbosacral vertebra of a chick given the deficient diet and vitamin $A$ for 20 days. The periosteum is fibrous with a single or double row of osteoblasts.

\section{Plate 3}

The photomicrograph (a) was stained by haematoxylin and eosin; $(b)$ and $(c)$ are freehand sections of unfixed tissue.

(a) Longitudinal section of the ventral surface of the arch of the ninth lumbosacral vertebra of a chick given the vitamin A-free diet for 22 days. A nodule of cartilage has formed below the periosteum.

(b) Transverse sections of the first four lumbosacral vertebrae of a chick given the deficient diet for 28 days. The tissue was unfixed. The scale is in $\mathrm{mm}$ (cf. (c)).

(c) Transverse section of the first four lumbosacral vertebrae of a chick given the deficient diet supplemented with vitamin $\mathbf{A}$ for $\mathbf{2 8}$ days. The tissue was unfixed. The scale is in $\mathrm{mm}$. The appearance is similar to that of the vertebrae of the deficient chick, shown in $(b)$.

\section{REFERENCES}

Barnicot, N. A. \& Datta, S. P. (1956). In The Biochemistry and Physiology of Bone, pp. 5I5, 5I6.

[H. G. Bourne, editor.] London and New York: Academic Press Inc.

Cammermeyer, J. (1961). Acta Neuropath. I, 245.

Carlton, W. W. \& Henderson, W. (1964). Avian Dis. 8, 48.

Covell, W. P. (1940). Laryngoscope Marseille 50, 632.

Fox, M. R. S. \& Briggs, G. M. (1960). F. Nutr. 72, 243.

Howell, J. McC. \& Thompson, J. N. (1965). Br. F. exp. Path. 46, i 8.

Howell, J. McC. \& Thompson, J. N. (1967). Br. F. exp. Path. 24, no. 4 (In the Press.)

Irving, J. T. (1956), Medsche. Klin. 51, 690.

Jungherr, E. (1943). Bull. Storrs agric. Exp. Stn no. 250.

Mellanby, E. (1944). Proc. R. Soc. B r32, 28.

Mellanby, E. (1950). A Story of Nutritional Research. Baltimore: Williams \& Wilkins.

Moore, T. (1957). Vitamin A, p. 326. Amsterdam: Elsevier.

Perlman, H. B. (1949). Archs Otolar. 50, 20.

Pratt, C. W. M. \& McCance, R. A. (I960). Br. F. Nutr. I4, 75.

Rigdon, R. H. (1952). Archs Path. 53, 239.

Stewart, R. J. C. (1965). Wld Rev. Nutr. Diet. 5, 275.

Wolbach, S. B. (1947). F. Bone Yt Surg. 29, 17 I.

Wolbach, S. B. \& Hegsted, D. M. (I952a). Archs Path. 54, 1.

Wolbach, S. B. \& Hegsted, D. M. (1952b). Archs Path. 54, I 3.

Wolbach, S. B. \& Hegsted, D. M. (I 952c). Archs Path. 54, 548.

Woollam, D. H. M. \& Millen, J. W. (1956). Br. F. Nutr. 1o, 355. 